\title{
Solvophobically-Driven Oligo(Ethylene Glycol) Helical Foldamers. Synthesis, Characterization, and Complexation with Ethane-1,2-Diaminium
}

\author{
Jun-Li Hou, ${ }^{\dagger}$ Mu-Xin Jia, ${ }^{\ddagger}$ Xi-Kui Jiang, ${ }^{\dagger}$ Zhan-Ting Li, ${ }^{\dagger} *$ Guang-Ju Chen ${ }^{\ddagger} * *$ \\ 'Shanghai Institute of Organic Chemistry, Chinese Academy of Sciences, \\ 354 Fenglin Lu, Shanghai 200032, China \\ ${ }^{2}$ Department of Chemistry, Beijing Normal University, Beijing 100875, China
}

\section{Supporting Information}

\section{Table of Contents}

Figure 1. The plot of the absorbance of oligomers 1a-1h against $\Phi \quad$ S2

Figure 2. Plot of the excimer intensity of $\mathbf{1 b}-\mathbf{1 h}$ vs $\Phi \quad$ S2

Figure 3. ${ }^{1} \mathrm{H}$ NOESY NMR spectrum of the mixture of $\mathbf{1 f}+\mathbf{1 9}$ in $\mathrm{CD}_{3} \mathrm{CN}$ 


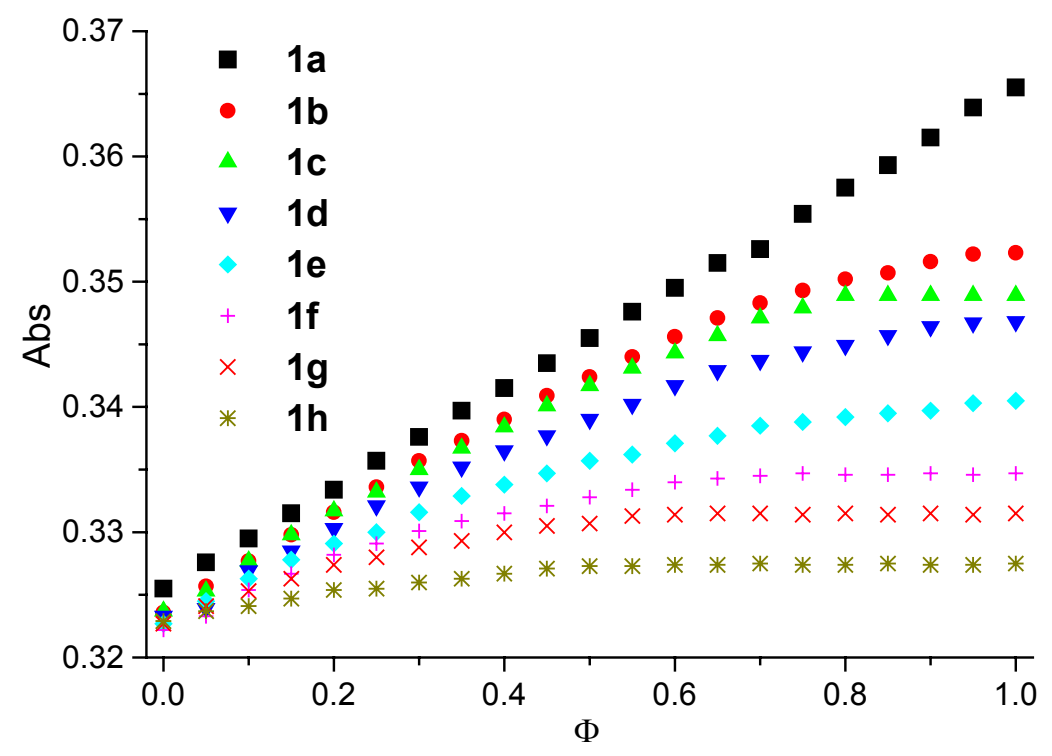

Figure 1. The plot of the absorbance $\left(323 \mathrm{~nm},[\mathrm{~Np}]=5.0 \times 10^{-5} \mathrm{M}\right)$ of oligomers $\mathbf{1 a}-\mathbf{1 h}$ against $\Phi$ at $25{ }^{\circ} \mathrm{C}$, highlighting the folding-induced hypochromic effect of the longer oligomers in chloroform and DMSO of high $\Phi(\Phi:$ DMSO fraction in the binary solvent system).

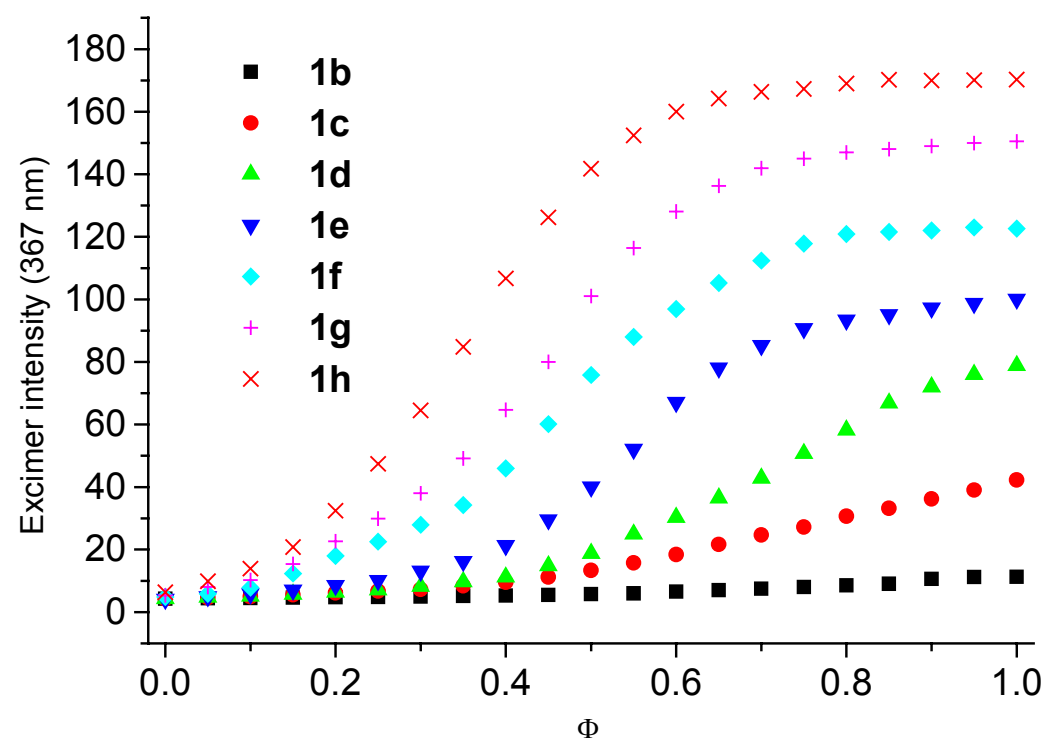

Figure 2. Plot of the excimer intensity of $\mathbf{1 b - 1 h}$ at $367 \mathrm{~nm}$ vs $\Phi$ in chloroform and DMSO at 25 ${ }^{\circ} \mathrm{C} . \lambda_{\mathrm{ex}}=280 \mathrm{~nm},[\mathrm{~Np}]=2.7 \times 10^{-6} \mathrm{M}(\Phi$ : DMSO fraction in the binary solvent system $)$. 


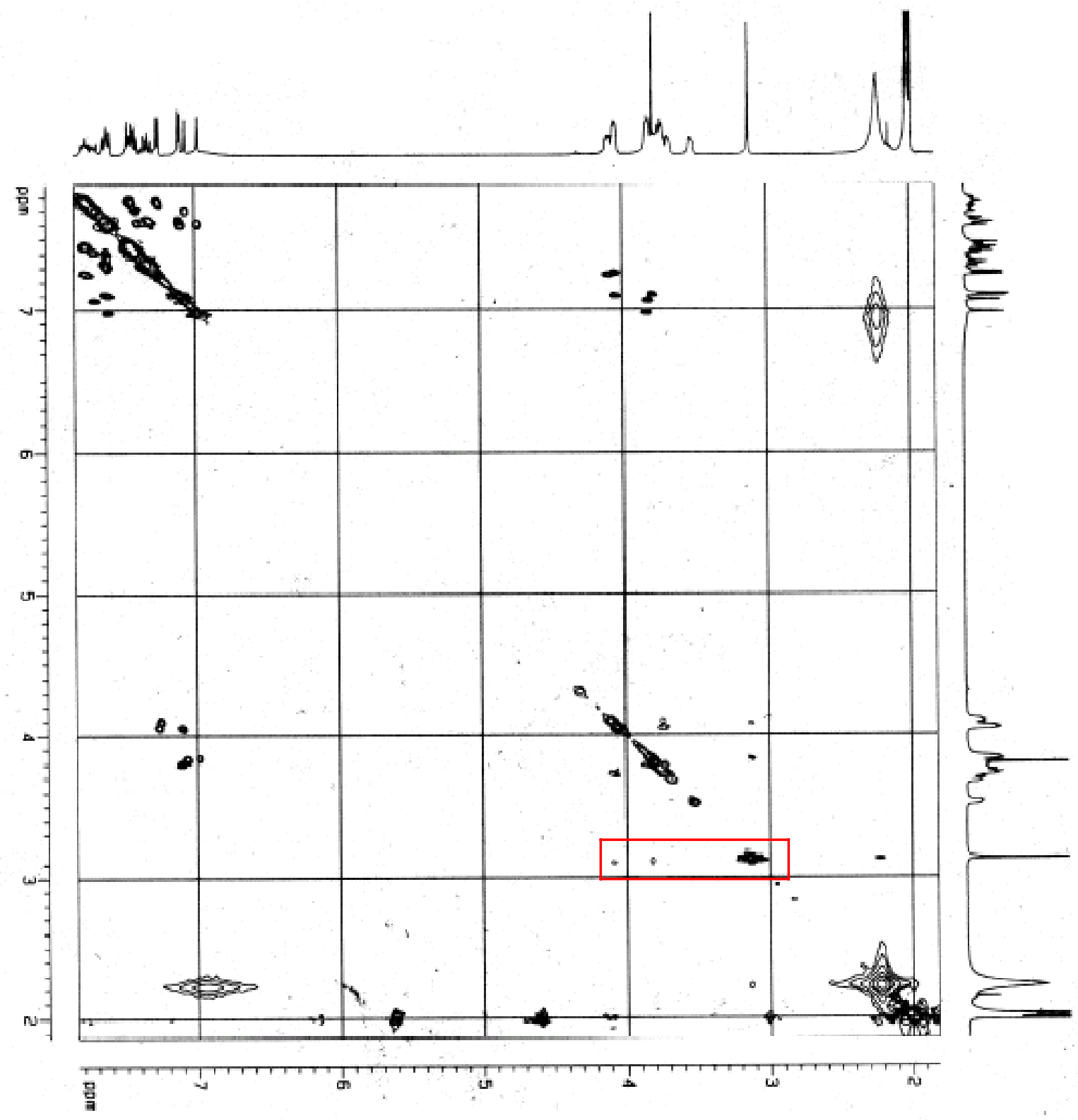

Figure 3. ${ }^{1} \mathrm{H}$ NOESY NMR spectrum $(400 \mathrm{MHz})$ of the mixture of $\mathbf{1 f}(3.0 \mathrm{mM})+\mathbf{1 9}(3.0 \mathrm{mM})$ in $\mathrm{CD}_{3} \mathrm{CN}$ at $25^{\circ} \mathrm{C}$ (mixing time $=1 \mathrm{~s}$ ). 